\title{
Interventions of health education in mothers of children with cerebral palsy
}

Open acess

1Universidade Federal do Ceará (UFC). Intern - Núcleo de Tratamento e Estimulação Precoce (NUTEP). Fortaleza, Ceará, Brasil.

2Universidade Federal do Ceará (UFC). Fisioterapeuta. PhD. Education. Departamento de Fisioterapia da Universidade Federal do Ceará (UFC). Fortaleza. Ceará, Brasil.

${ }^{3}$ Physiotherapist - Núcleo de Tratamento e Estimulação Precoce (NUTEP). Master. Child and adolescent health. Fortaleza, Ceará, Brasil.

${ }^{4}$ Universidade Federal do Ceará. Physiotherapist. PhD. Medical Sciences. Departamento de Fisioterapia da Universidade Federal do Ceará

Fortaleza, Ceará, Brasil.

${ }^{5}$ Psychologist - Núcleo de Tratamento e Estimulação Precoce (NUTEP).

Specialist in mental health and brief focal psychotherapy. Fortaleza, Ceará, Brasil.

\section{Corresponding author:}

michelinegirao@ymail.com

Manuscript received: 15 February 2017 Manuscript accepted: 10 May 2017

Version of record online: 06 September 2017

\author{
Micheline Maria Girão de Andrade ${ }^{1}$, Fabiane Elpídio de Sá2, Lêda \\ Maria da Costa Pinheiro Frota ${ }^{3}$, Kátia Virginia Viana Cardoso ${ }^{4}$, \\ Germana Maria de Alcântara Carleial ${ }^{5}$
}

\begin{abstract}
Introduction: The functional performance of children with cerebral palsy is directly influenced by the therapeutic guidelines offered to caregivers.
\end{abstract}

Objective: To evaluate the impact of educational health interventions in mothers of children with cerebral palsy about the guidelines of care.

Methods: A qualitative interventional study developed in three stages between April and October of 2015 in the Núcleo de Tratamento e Estimulação Precoce of the Universidade Federal do Ceará, Brazil. The participants were six mothers of children with cerebral palsy. In the first stage we used the technique of individual semi-structured interviews, full recorded and transcribed for the apprehension and exploration of the speeches; In the second stage, taking into account the saturation and categorization of the speeches, a protocol was developed and applied by the researchers divided into eight interventions of health education in the group of mothers then in the third stage the individual interviews were redone for new exploration and comparison of speeches. The analysis of the data of the speeches was made through content analysis according to the proposal of Bardin.

Results: Satisfaction reports on receiving care, improvements in the handling of children, greater safety in the implementation of therapeutic guidelines, better perception about the development of the child with the treatment and higher concern with self-care.

Conclusions: The educational interventions promoted a better perception of mothers of children with cerebral palsy about the therapeutic orientations received from the health team, since they are based on the family-centered model offering conditions to the mothers for the confrontation and reduction of the physical overload, emotional and psychological; through self-care in health, and information about means and adaptations for the adequate continuity of child care.

Keywords: cerebral palsy, knowledge, caregivers, health education 


\section{INTRODUCTION}

The child with cerebral palsy experiences physical, sensory and sometimes cognitive limitations; the brain injury affects the individual from the beginning of life, and although it is not progressive, it has a high level of incapacitation, negatively impacting quality of life and requiring caregivers and family members a minimum of knowledge, dedication and coping capacity ${ }^{1}$. Functional performance of children with cerebral palsy is directly influenced by the therapeutic guidelines offered to caregivers $^{2}$. Health education thus becomes a vital component of early intervention; based on a familycentered approach or practice, providing mechanisms and strategies for family empowerment, intensity and continuity of care, promoting better family adaptation to children with disabilities, lower levels of stress, anxiety and family frustration ${ }^{3}$; In addition to providing children with many and better opportunities for active practice within their daily routines ${ }^{4}$.

It is understood today that the health team must be able to understand the experiences and guide the parents and/or caregivers of children with disabilities; to listen to them and to recognize them as part of a joint strategy of coping and comprehensive rehabilitation of these children $^{5}$. Avoiding harmful attitudes, such as passivity,

\section{METHODS}

It is an interventional research with a qualitative and descriptive approach ${ }^{11}$. The research followed the Resolution $n^{\circ} 466 / 12$ of the National Health Council on research involving human beings and Code of Ethics of Physiotherapy and Occupational Therapy, it was approved by the Comitê de Ética da Universidade Federal do Ceará, number 42515715.4.0000.5054.

The study was developed between April and October 2015, at the Núcleo de Tratamento e Estimulação Precoce - NUTEP, which works at the Paediatrics Outpatient Clinic of the School of Medicine of the Universidade Federal do Ceará - UFC. The selection of the study sample was initiated through the analysis of medical records available by the institution. Twentyfour mothers present in the waiting room were invited by the researchers and staff of the Social Service of the institution to participate in the intervention. After clarification about the research, six (06) mothers aged between 20 and 40 years, with children diagnosed with cerebral palsy, in varying degrees of motor, cognitive and sensory impairment, attended and monitored by NUTEP, agreed to participate in the study. The inclusion criterion was to be the mother of a child with a defined diagnosis of cerebral palsy with GMFCS between levels III and $\mathrm{IV}$, with at least 06 (six) months of treatment; besides the agreement to participate in the research, the previous reading and signing of the Term of Free and Informed Consent.

All the participants presented educational level of complete elementary education, with ages between 20 and 40 years and low socioeconomic level. Once included where parents and families become mere replicators of what is oriented to them, without the actual knowledge of the condition of their children and/or the purpose of the guidelines. The lack of horizontality and the distance between the health specialist and the family still represent the main obstacle for the therapeutic guidelines to be understood and performed effectively within the routine of children with cerebral palsy; Delaying and/or even hindering good treatment outcomes or a favorable prognosis ${ }^{6}$. It is necessary to define the health strategies, interventions and the support offered by the health team to the parents of children with disabilities ${ }^{7,8}$.

The present study has the purpose of evaluating the effects of educational health interventions in the knowledge of the mothers of children with cerebral palsy on the guidelines received from the health team during the treatment of their children. Whereas parental training is still scarce in the context of basic childcare services; the great relevance of family-centered approaches and social support within this context ${ }^{9,10}$, the results are expected to provide health education strategies and actions to foster the empowerment and knowledge of caregivers and families of children with cerebral palsy, strengthening the bonds and conditions necessary for the development of the child.

in the sample, the mother was initially invited to attend a room provided by the NUTEP for an individual meeting with one of the researchers during the care of the child for the beginning of the procedures and stages of the study. The research was carried out in three stages divided into categories as described below: In the first stage the individual interviews were recorded and transcribed in full for the apprehension and exploration of the discourses; In the second stage, taking into account the saturation and categorization of the speeches, a protocol was developed and applied by the researchers divided into eight (08) health education interventions in the group of mothers and in the third stage the individual interviews were redone to new exploration and comparison of speeches. The discourses of the mothers to be investigated and interpreted were collected in the first and third stages (before and after the educational interventions of the second stage).

The collected material of the speeches went through a detailed content analysis in view of the steps proposed by Bardin ${ }^{12}$ : pre-analysis, material exploration, treatment of results and interpretation; Each report was heard and transcribed in its entirety and then divided into categories for later significance and interpretation of the discussed on the basis of the literature. All participants in the survey had the right to confidentiality and privacy; thus ensuring their preserved identifications. For this we use designations like: Mother 01 , Mother $02 \ldots$ Mother $06 \ldots$

\section{1nd stage of the study:}

The initial data to be investigated were collected 
from April to May 2015 through individual interviews and recorded with the consent of the participants. The interview had a guiding imperative or request: "Tell me about your child's condition and the directions you received or are receiving from the therapists who attend you here at NUTEP; their difficulties, the positive and negative points in the service". From then on further questions were asked and reformulated as the conversation was ongoing. The interviews had an average duration of ten minutes.

The following category was taken from the saturation of the speeches of the 1st stage and was used as guiding for the development of an interventional protocol: The resistance and the needs of the mothers before the therapeutic orientations.

Based on the categorization of the saturation of the speeches from the first moment of the research and interpretation of the data collected, a protocol was elaborated, divided into eight (08) educational health interventions focused on the main needs reported by the mothers in the first interviews. Then, participants were approached and invited to be present at the second moment of the research and to begin the interventional stage of the study.

\section{2nd stage of the study:}

The protocol with eight (08) educational health interventions applied by researchers in the group of six (06) mothers progressed from June to July 2015, once a week, on Tuesday mornings for two months; taking into account the categorization of the speeches of the first stage, focusing on a horizontal approach with therapeutic orientations and involving activities such as: conversation circles (with exchange of experiences), interactive lectures and videos about varied and multidisciplinary themes

\section{RESULTS}

After the meticulous analysis of the speeches seized in two moments of the interview, two categories appeared in the text previously:

Category 1: extracted from the initial interviews of the first stage (before interventions).

Category 2: extracted from the final interviews in the third stage of the research (after-educational interventions).

Category 1- The mothers mentioned in their speeches that some guidance received from the specialist team are perceived as orders and/or also a critique to the care given to the child, making it difficult to understand the benefit of this information. It is observed a great resistance to the confrontation of these mothers with the condition of the child leading to high levels of stress, as well as overprotection, making it difficult to adhere to treatment and guidelines for home:

[...] in the beginning, I received the guidelines and I do not know if it was guidance or was a critique ... I do not know if it was a question or was a critique... (Mother 01).

[...] I have difficulty feeding my son and putting him on his feet [...] I feel that he does not accept within the context of cerebral palsy.

The interventions were divided into the following themes: 1. Definitions, dysfunctions, treatment and prognosis; 2. Early stimulation; 3. Sensory, visual and auditory stimulation; 4. Stimulation of language; 5. Food; 6. Positioning, handling and appropriate postures of the child and caregiver; 7. Proper use of orthoses; 8. Environmental adaptations, including furnishings and specific materials for home continuity in the treatment of children. 10. Relaxation techniques ${ }^{13}$, stimulation and self-care guidelines for caregiver mothers (always applied at the end of all interventions). Then moving on to the last step of the research.

\section{3nd stage of the study:}

After completion of the eight (08) interventions, in September 2015 the mothers were again invited to carry out new interviews, with the same guiding question as the first moment of the study: "Tell me about the condition of your child and the directions you received or are receiving from the therapists who attend you here at NUTEP; their difficulties, the positive and negative points in the service “. The speeches were again full recorded and transcribed. Content analysis ran from September to October 2015; and as in the first stage of the research, in accordance with the steps proposed by Bardin ${ }^{12}$.

From the speeches and reports of the mothers in the interviews of the third stage of the study emerged the category strategies of orientation and support: difficulties and needs of the mothers; from them the researchers made a correlation between the discourses in the initial and final moment of the study in search of relevant results. Emphasizing that the analysis of discourse and its process of signification is not only a construction of meanings, but of processes of construction of reality ${ }^{14}$.

physiotherapy very well [...] they tell us to do it, but if he does not want it, I will not do it by force [...] who knows about my son, I am [...] (Mother 06).

Knowledge about the objectives of the guidelines is not always understood, as well as about the role played by the specialist team. Therapeutic guidelines reach mothers often with vertically language and are often perceived as a continuous requirement of being submissive to the health care team ${ }^{15}$

Recent studies consider that health staff should help parents cope with their responsibilities through horizontal dialogue and interventions based on family values, preferences, priorities and needs ${ }^{16}$; consolidating the therapeutic alliance between the family, the child and the health care team.

[...] some guidelines I do [...] a little, because of the routine that we have ... we do not have much free time to do all the time [...] I do not have time [..] (Mother 01).

[...] I do not know what the therapists' function is, nor the reason for the guidelines [...] I see them playing with the children ... I do not know if the treatment is just that or if there is something else [...] (Mother 02). 
Excerpts from the reports give indications of claimings by family members and health staff; which perhaps justifies the surprise, and satisfaction in receiving a closer look at their needs. There are also losses in physical health, social participation and the need for a network of social and family support; as well as a better reception on the part of the institution. Despite the guidelines offered by caregivers to be included in care, the mother's stressful routine makes it difficult to put these guidelines into practice, as expressed in the following speeches:

[...] we can never do $100 \%$ everything that is sent to us $[. .$.$] time that I$ have is to do things at home $[\ldots]$ it is very tiring $[\ldots]$ we even try $[\ldots]$ but can not keep to see if the child has some progress [...] (Mother 02).

[...] the therapists tell me that I have to do physical exercises [...] but I can not do [...] I do not have anyone stay with him [...] (Mother 03).

[...] to put my son on his feet mainly, I need help for this [...] I'm alone with him all day, so it's complicated ... it's already affecting me even physically, because now I live with back pain because of his weight [...] (Mother 06).

[...] it is good to know that someone is worried about our opinions [...] so it improves for everyone [...] (Mother 03).

Studies indicate that parents of children with cerebral palsy perceive their own poor health and have symptoms of depression, stress, and muscle pain; which leads to a poor quality of life $\mathrm{e}^{17}$; the stress routine of care a child with disabilities imposes has a negative impact on the health of their parents ${ }^{18}$. It is necessary to establish an effective network of multiprofessional support services for children with motor, cognitive and sensory disorders and their families. Interventions should address parental needs from the perspective of routine childcare, in view of the fact that they should enable their capacities, reducing the negative impact and harm caused by the condition of children and the affected families.

The educational interventions were based on the statements extracted in the first stage of the research, these were guided by the parental needs, being consolidated in the category 2 as follows:

Category 2 - Guidance and support strategies: difficulties and needs of mothers:

Mothers demonstrate improved perception and recognition of developmental progression in children with treatment; It is considered that receiving clear, accurate and horizontal information is important for mothers in the treatment adherence of their children? ${ }^{7}$.

[...] I always had guidance on how to sit my daughter, give food, how to carry on the arm ... before I did everything upside down [...] only after I got it right [..] (Mother 05).

[...] the guidelines help me [...] because I am always learning to help him [...] (Mother 01).

[...] my son has already developed very well in a year that he is here [...] and with the guidelines I can already position him correctly [...] will already be sitting in a corner without my support [..] All this is already a great help to me [...] (Mother 03).

[...] I notice that he learns faster now [...] (Mother 01).

The mothers still reported little ability and/or knowledge to develop necessary adaptations in relation to the equipment or materials indicated for the development of the child. However, there were post-intervention reports of an improvement in the handling of children; greater stimulation and safety in the attempts to execute the therapeutic guidelines. Providing effective guidance and information to families is often a challenge for the health care team; this process needs to be improved to facilitate the process of family empowerment in relation to the care provided to children ${ }^{5}$.

[...] some things I am learning now [...] when I see that there is some kind of difficulty I stop [...] (Mother 04).

[...] there is activity that they do here, which at home I can not do [...] because I do not have all the material [...] (Mother 06).

$[\ldots]$ now I try to sit down with her $[. .$.$] every day$ trying to do something that the therapist spoke ... to help my daughter in some way [Mother 05].

[...] we get stimulated at home, with activities [...] I made a book that the therapist taught with engravings, letters, numbers, figures. We have heard [...] (Mother 04).

[...] it is also an incentive for us to do things at home and not only here ... an activity that you think does not change anything, it changes the child very much [...] (Mother 03).

Greater concern for self-care emerged from maternal discourses after interventions. Research calls attention to the importance of a more careful look at caregivers; emphasizing the physical and psychological deterioration on the caregiver results in several health problems ${ }^{19}$. It is extremely important an urgent and profound change in the multiprofessional approach currently used; which takes into account clinical aspects and their psychosocial, environmental and spiritual repercussions, both for the disabled person and for his/her family and caregivers ${ }^{20}$.

[...] we live for the children, but there at the time of relaxation we remembered that we also existed [...] (Mother 02).

[...] I was very surprised by the moment of relaxation ... in the middle of our routine of the day that was our only moment of calm [Mother 05].

[...] I should have had more time for these interventions ... I think there is still much to teach us [...] (Mother 04).

[...] the part of the relaxation that she did with us always in the end, this has to have [...] the therapist also said that we had to take one day for us ... we encouraged people to take care of herself, to go to the hairdresser, to paint her nails, to go out with her friends, these things ... I loved it, I liked it [...] (Mother 03).

The condition of a child with cerebral palsy does not change easily; and even with all possible accompaniments, the child spends most of his time in his family environment; demanding from the families and 
caregivers mothers an ability to adapt more and more; this fact therefore demands from the institutions that meet this profile, a process of continuous surveillance in offering also, on an ongoing basis, adequate family support, through interventions with updated information and guidelines throughout the treatment of the affected child, and not only at the time of admission. An adequate social support offered to families of children with cerebral palsy seems to prevent and attenuate the negative impact and stress situations; their absence culminates in feelings of sadness, anger and abandonment, negatively affecting the family routine and the treatment of children ${ }^{21}$.

When it comes to child care, families and caregivers have always been in the background ${ }^{22}$. The maintenance of a similar knowledge and horizontal dialogue between parents, families and multidisciplinary health care team seems to be the greatest obstacle and/or challenge for the acquisition of efficient and effective strategies that promote a better quality of life for families and caregivers, a real home care continuity and a better prognosis in the treatment of children with cerebral palsy. Approaches that do not address meaningful learning ${ }^{23}$ for parents and caregivers, and where interventions do not address the general context in which families are embedded, are doomed to fail; and only lead health professionals to commit themselves with orientations ${ }^{24,25}$.

[...] our meetings were really the much desired feedback moment I expected from NUTEP [...] because I realized that at the beginning when we come in, the directions and feedback is greater, but in time, they go decreasing [...] this is bad, because we get lost and do not know what to do (Mother 01).

\section{CONCLUSION}

The research revealed that the guidelines received by the mothers from the health team study need to be appropriate to the environment of each child and their family. Demonstrating that in addition to the importance of parental educational interventions in health it is essential to carry out continuous training for the early stimulation teams with a focus on the family-centered approach.

Health education strategies that enable the unique approach of children with cerebral palsy lead to the development of a therapeutic alliance with a view to welcoming and linking families and services; empowering them in the face of the contingent care of these children, since services are in high demand for care and often fail to respond to the needs of the child and his caregivers.

In this sense, it was verified that the research serves as a subsidy for the specialist practice and continuity of its proposals; since the health education interventions developed and implemented in this study promoted a better
[...] NUTEP should create a room for mothers to talk ... teach us how to avoid our pains or get sick, face our daily activities with our children ... we need to be well to help in the treatment of children at home (Mother 03).

[...] I participated in the meetings to really learn, and to use with my daughter [...] to know if what I did was wrong ... we had 30 minutes to receive information, clear the doubts and observe the procedures [...] that we did not see in our routine because we could not enter the room at the time of care [...] (Mother 05). [...] when we go to pick up the children and try to ask the therapists something, they do not have much time to respond $[\ldots]$ or they respond anyway $[\ldots]$ they say things that I do not think are important [...] some things I take to relevance, others not [...] (Mother 04).

It is important to emphasize the sharing of intimacy during the interviews and during their participation in the interventions for mothers often provoked the feeling of invasion, fear of not provoking empathy, being judged or considered incompetent in the performance of her role as mother; making it clear that aspects permeate the whole situation; and the psychological and emotional aspect seems to be the crucial point to be observed, influencing in a significant way the adherence of these mothers of children with cerebral palsy to the parental interventions, and the way they see the therapeutic orientations received. Therefore, it is considered a limitation for this study the reduced time for the execution of the parental interventions.

perception of the mothers of children with cerebral palsy about the therapeutic orientations received from the health care team, since they are based on the family-centered model and offer conditions for the mothers to the development of better coping and reduction of physical, emotional and psychological overload; through self-care, and information about means and adaptations for the adequate continuity of child care.

It is suggested to use studies with valid tools to evaluate the family needs of children with physical disabilities that can subsidize intervention protocols that guarantee educational interventions focused on the priorities of families.

\section{Interest conflicts}

The authors declare no conflicts of interest in this study.

\section{REFERENCES}

1. Surender S, Gowda V, Sanjay K, Basavaraja G, Benakappa N, Benakappa A. Caregiver-reported health-related quality of life of children with cerebral palsy and their families and its association with gross motor function: A South Indian study. J Neurosci Rural Pract. 2016;7(2):223-7. DOI: http://dx.doi.org/10.4103/0976-3147.178657 
2. Brianeze ACGS, Cunha AB, Peviani SM, Miranda VCR, Tognetti VBL, Rocha NACF, et al. Efeito de um programa de fisioterapia funcional em crianças com paralisia cerebral associado a orientações aos cuidadores: estudo preliminar. Fisioter Pesqui. 2009;16(1):40-5. DOI: http://dx.doi.org/10.1590/S1809-29502009000100008

3. Vuorenmaa M, Perälä M-L, Halme N, Kaunonen M, Åstedt-Kurki P. Associations between family characteristics and parental empowerment in the family, family service situations and the family service system. Child Care Health Dev. 2016;42(1):25-35. DOI: http://dx.doi.org/10.1111/cch.12267

4. Morgan C, Novak I, Dale RC, Guzzetta A, Badawi N. GAME (Goals - Activity - Motor Enrichment): protocol of a single blind randomised controlled trial of motor training, parent education and environmental enrichment for infants at high risk of cerebral palsy. BMC Neurol. 2014;14:203. DOI: http://dx.doi.org/10.1186/s12883-014-0203-2

5. Kruijsen-Terpstra AJA, Ketelaar M, Boeije H, Jongmans MJ, Gorter JW, Verheijden J, et al. Parents' experiences with physical and occupational therapy for their young child with cerebral palsy: a mixed studies review. Child Care Health Dev. 2014;40(6):787-96. DOI: http://dx.doi.org/10.1111/cch.12097

6. Vuorenmaa M, Halme N, Perälä M-L, Kaunonen M, Åstedt-Kurki P. Perceived influence, decision making and access to information in family services as factors of parental empowerment: a cross-sectional study of parents with young children. Scand J Caring Sci. 2016;30(2):290-302. DOI: http://dx.doi.org/10.1111/scs.12243

7. Jansen SLG, van der Putten AAJ, Vlaskamp C. What parents find important in the support of a child with profound intellectual and multiple disabilities. Child Care Health Dev. 2013;39(3):432-41. DOI: http://dx.doi.org/10.1111/j.1365-2214.2012.01381.x

8. Alpino AMS, Valenciano PJ, Furlaneto BB, Zechim FC. Orientações de fisioterapia a mães de adolescentes com paralisia cerebral: abordagem educativa para o cuidar. Rev Bras Educ Espec. 2013;19(4):597-610. DOI: http://dx.doi.org/10.1590/S1413-65382013000400009

9. Vonneilich N, Lüdecke D, Kofahl C. The impact of care on family and health-related quality of life of parents with chronically ill and disabled children. Disabil Rehabil. 2016;38(8):761-7. DOI: http://dx.doi.org/10.3109/09638288.2015.1060267

10. Wu S, Wyant DC, Fraser MW. Author Guidelines for Manuscripts Reporting on Qualitative Research. J Soc Social Work Res. 2016;7(2):405-25. DOI: http://dx.doi.org/10.1086/685816

11. World Health Organization (WHO). International Classification of functioning, disability and health: ICF. World Health Organization; 2001.

12. Bardin L. L'analyse de contenu. 2 édition. Paris: Presses universitaires de France; 2013.

13. Jacobs GD. The Physiology of mind-body interactions: the stress response and the relaxation response. J Altern Complement Med. 2004; 7(Suppl.1):S83-92. DOI: https://dx.doi.org/10.1089/107555301753393841

14. Almeida ML de. Análise de dados na pesquisa qualitativa: desafios ao pensamento criativo. Arxius Cienc Soc. 2014; (31):143-54.

15. Custodio N, Marski BSL, Abreu FCP, Mello DF, Wernet M. Interações entre profissionais de saúde e mães de prematuros: influência no cuidado materno. Rev Enferm UERJ. 2016;24(1):e11659 DOI: http://dx.doi.org/10.12957/reuerj.2016.11659

16. Trabacca A, Vespino T, Di Liddo A, Russo L. Multidisciplinary rehabilitation for patients with cerebral palsy: improving long-term care. J Multidiscip Healthc. 2016;9:455-62. DOI: http://dx.doi.org/10.2147/JMDH.S88782

17. Yilmaz H, Erkin G, Nalbant L. Depression and anxiety levels in mothers of children with cerebral palsy: a controlled study. Eur J Phys Rehabil Med. 2013; 49(6):823-7.

18. Czupryna K, Nowotny-Czupryna O, Nowotny J. Back pain in mothers of cerebral palsied children. Ortop Traumatol Rehabil. 2014;16(5):497-505. DOI: http://dx.doi.org/10.5604/15093492.1128840

19. 19. Garip Y, Ozel S, Tuncer OB, Kilinc G, Seckin F, Arasil T. Fatigue in the mothers of children with cerebral palsy. Disabil Rehabil. 2017;39(8):757-62. DOI: http://dx.doi.org/10.3109/09638288.2016.1161837

20. Whittingham K, Wee D, Sanders MR, Boyd R. Predictors of psychological adjustment, experienced parenting burden and chronic sorrow symptoms in parents of children with cerebral palsy. Child Care Health Dev. 2013;39(3):366-73. DOI: http://dx.doi.org/10.1111/j.1365-2214.2012.01396.x.

21. Al-Gamal E, Long T. Psychological distress and perceived support among Jordanian parents living with a child with cerebral palsy: a cross-sectional study. Scand J Caring Sci. 2013;27(3):624-31. DOI: http://dx.doi.org/10.1111/j.1471-6712.2012.01071.x 
22. Rosenbaum $P$, Gorter JW. The "F-words" in childhood disability: I swear this is how we should think! Child Care Health Dev. 2012;38(4):457-63. DOI:http://dx.doi.org/10.1111/j.1365-2214.2011.01338.x

23. Ausubel DP. The acquisition and retention of knowledge: a cognitive view. Dordrecht: Springer Netherlands; 2000.

24. Arcuri GG, McMullan AE, Murray AE, Silver LK, Bergthorson M, Dahan-Oliel N, et al. Perceptions of family-centred services in a paediatric rehabilitation programme: strengths and complexities from multiple stakeholders. Child Care Health Dev.. 2016;42(2):195-202. DOI: http://dx.doi.org/10.1111/cch.12308

25. Arango P. Family-centered care. Acad Pediatr. 2011;11(2):97-9. DOI: http://dx.doi.org/10.1016/j.acap.2010.12.004

\section{Resumo}

Introdução: O desempenho funcional de crianças portadoras de paralisia cerebral sofre influência direta das orientações terapêuticas oferecidas aos cuidadores. Objetivo: Avaliar os efeitos de intervenções educativas em saúde no conhecimento de mães de crianças com paralisia cerebral sobre as orientações recebidas da equipe multiprofissional em relação ao tratamento de seus filhos.

Método: Estudo intervencional qualitativo desenvolvido em três etapas entre os meses de abril a outubro de 2015 no Núcleo de Tratamento e Estimulação Precoce da Universidade Federal do Ceará. As participantes foram seis mães de crianças com paralisia cerebral. Na $1^{\text {a }}$ etapa utilizou-se a técnica de entrevistas individuais semiestruturadas gravadas e transcritas na íntegra para apreensão e exploração dos discursos; na $2^{\circ}$ etapa, levando-se em conta a saturação e categorização dos discursos, foi desenvolvido e aplicado pelas pesquisadoras um protocolo dividido em oito intervenções de educação em saúde no grupo de mães e na $3^{a}$ etapa as entrevistas individuais foram refeitas para nova exploração e comparação dos discursos. A análise dos dados dos discursos foi feita por meio de análise de conteúdo conforme a proposta de Bardin.

Resultados: Relatos de satisfação em receber o cuidado, melhoras no manuseio das crianças, maior segurança na execução das orientações terapêuticas, maior percepção sobre o desenvolvimento da criança com o tratamento e maior preocupação com o autocuidado.

Conclusão: As intervenções promoveram uma melhor percepção das mães de crianças com paralisia cerebral acerca das orientações terapêuticas recebidas da equipe de saúde, na medida em que se baseiam no modelo centrado na família oferecendo condições às mães para o o enfrentamento e redução da sobrecarga física, emocional e psicológica; através do autocuidado em saúde, e informações acerca de meios e adaptações para a continuidade adequada da assistência à criança.

Palavras-chave: paralisia cerebral, conhecimento, cuidadores, educação em saúde

๑ The authors (2017), this article is distributed under the terms of the Creative Commons Attribution 4.0 International License (http://creativecommons.org/licenses/by/4.0/), which permits unrestricted use, distribution, and reproduction in any medium, provided you give appropriate credit to the original author(s) and the source, provide a link to the Creative Commons license, and indicate if changes were made. The Creative Commons Public Domain Dedication waiver (http://creativecommons.org/ publicdomain/zero/1.0/) applies to the data made available in this article, unless otherwise stated. 